Transactions of the Royal Society of Tropical Medicine and Hygiene, Vol. 72, No. 2, 1978

\title{
Stability of faecal egg excretion in Schistosoma mansoni infection*
}

\author{
MaURICIO LIMA BaRRETo \\ Department of Preventive Medicine, Faculty of Medicine, Federal University of Bahia, Salvador, Bahia, Brazil \\ Jose Teixeira Franca Silva \\ Nucleo de Pesquisas da Bahia, Fundacao Oswaldo Cruz, Salvador, Bahia, Brazil
}

KenNeth E. MotT

Department of Tropical Public Health, Harvard School of Public Health, Boston, Massachusetts U.S.A.

AND

J. StaufFer Lehman, JR.

The Edna McConnell Clark Foundation, New York, New York, U.S.A.

\begin{abstract}
Summary
Stability of Schistosoma mansoni egg excretion was studied in 23 residents of a rural endemic area in North-east Brazil where the over-all prevalence rate was $87 \%$ and the peak geometric mean egg excretion was $308 \mathrm{eggs} / \mathrm{ml}$ (Bell method) in the 10 to 14-year-old age group. Stool examinations by the Kato method were performed for three to four consecutive days each month for three consecutive months. Both raw and transformed data showed significant stability of $S$. mansoni egg excretion from day to day and month to month in this population. A single Kato examination detected $68 \%$ of individuals who were excreting more than 400 eggs per gramme. Although $S$. mansoni egg excretion is stable over time, identifying individuals with high egg excretion in endemic populations requires sensitive quantitative methods.
\end{abstract}

\section{Introduction}

In studies on Manson's schistosomiasis, quantitative egg counts are now widely used, and levels of egg excretion are utilized as an index of the intensity of infection. CIIIEVER's (1968) post-mortem study in Brazil demonstrated unequivocally that the worm load was a factor which correlated directly with the severity of the disease due to infection with Schistosoma mansoni.

Subsequent investigations performed in various endemic areas have repeatedly shown a relationship between faecal egg counts and the morbid consequences of the infection. Kloetzel (1974) has proposed that a minimum egg count be a criterion to determine the use of "selective and preventive chemotherapy" in ages at maximal risk. This thesis has been elaborated by WARRFN \& MAHMOUn (1976) and they suggested that rapid quantitative techniques be deployed in the field to identify those heavily infected individuals at risk of developing severe disease, thus qualifying for "targeted mass treatment".

Confidence in the use of such strategies assumes that faecal egg excretion is reasonably stable and that heavily and lightly infected persons can be identified and segregated on the basis of one or two parasitological examinations. MCCULLOUGH \& BRADLEY (1973) elegantly demonstrated such stability in $S$. haematobium infections in Tanzania, but few data on longitudinal egg excretion in infections with $S$. mansoni are available. The present investigation employed an egg-counting technique appropriate for use in the field and examined short term variation in $S$. mansoni egg excretion by individuals living in an endemic area.

\section{Population and methods \\ Study Area and Population}

The individuals studied came from a rural population in north-east Brazil being followed longitudinally for morbidity due to schistosomiasis mansoni and Chagas's disease. The study area is located in the municipio (county) of Castro Alves, State of Bahia, and is highly endemic for schistosomiasis and Chagas's disease. The area and the epidemiological methods employed have becn described (LEHMAN et al., 1976; MoTr et al., 1976).

A sub-population was chosen in an area which in 1974 contained 120 individuals with an over-all prevalence of $S$. mansoni infection of $87 \%$; the 10 to 14-year-old age group had a peak geometric mean egg excretion of $308 \mathrm{eggs} / \mathrm{ml}$ as calculated by the Bell method (BELL, 1963) of faeces. In 1976, 23 infected individuals were selected on the basis of previous egg counts using a table of random numbers with the objective of studying persons with high, medium and low levels of egg excretion. Each individual entering the study agreed to provide stool specimens on three consecutive days for each of three consecutive months (August, September and October of 1976). In instances where fewer than three stools were provided in a three-day period, a fourth day was added to obtain

* The Harvard component is supported by a grant from The Wellcome Trust, under the direction of Dr. Thomas H. Weller, and its collaborative activities in Brazil are under the aegis of the Pan American Health Organization. 
Table I-Individual characteristics of 23 individuals according to age, sex, number of Kato examinations performed over 3 months and analysis of $S$. mansoni egg count data for the entire period. Individuals are listed according to increasing mean counts.

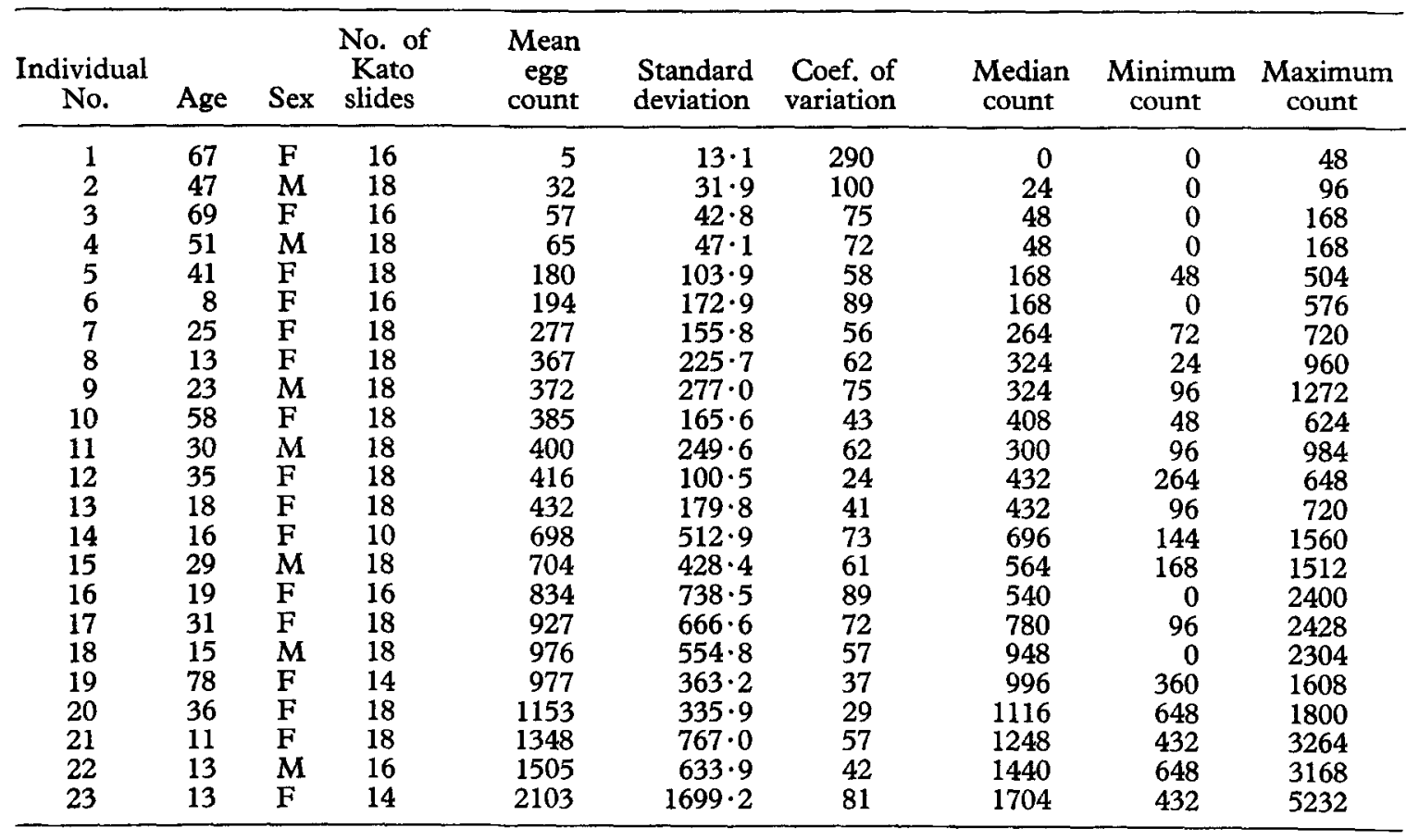

additional samples. In general, compliance was excellent; two of us (M.L.B. and J.T.F.S.) supervized stool collections in the field.

\section{Method of Stool Examination}

The Kato egg count method (MARTIN \& BEAvER, 1968) as modified by KATZ et al. (1972), for which a kit is available commercially (KIT-AK, AK Industria e Comercio Ltda., Belo Horizonte, Minas Gerais, Brazil), was utilized. In this method, faeces are strained through nylon gauze to remove debris and then placed in a plastic template which delivers a fixed stool volume (about $40 \mathrm{mg}$ ) on to a glass slide. The sample is covered with a cellophane coverslip $(22 \times 33 \mathrm{~mm})$ impregnated with an aqueous solution of glycerol and malachite green. Slides are inverted and pressed on to a bed of absorbent paper, turned face up and allowed to clear for at least six hours. Slides are examined microscopically using a magnification of $100 \times$. The number of $S$. mansoni eggs per slide is multiplied by a factor of 24 to obtain the number of eggs per gramme of faeces. All slides were read within 30 days of collection. Two slides were prepared from each faecal specimen and read independently. All slides were examined by one observer (M.L.B.) who randomly re-read a subsample to examine concordance with the first reading.

\section{Statistical Methods}

All data werc tabulated, and the means and variances of egg counts for individuals were calculat- ed on the basis of the number of slides read. In order to render the variances independent of the means and to achieve normal distributions, Taylor's power law (TAYLOR, 1961) was used and the appropriate transformation performed. Subsequently, standard statistical methods, such as correlation coefficient and Student's $t$ test, were used to compare grouped data. In general, the treatment of data followed that of MCCullough \& BRADLEY (1973), as the objectives of our work on $S$. mansoni egg excretion and their investigations on $S$. haematobium egg excretion were similar.

\section{Results}

Table I presents a summary of the grouped data accumulated for each individual during the study, based on the number of slides counted. Within this population there was a spectrum of mean egg counts, ranging from four to 2,103 eggs per gramme. The individual mean and median egg counts coincided reasonably well, indicating that the distribution of egg counts for each individual was nearly symmetrical around the mean. The coefficients of variation (standard deviation/mean $X$ 100 ) within the sample demonstrated considerable individual variation in egg counts throughout the study period, and the average coefficient of variation was around $70 \%$. For many persons, there was a considerable spread between minimum and maximum egg counts.

The mean, standard deviation and coefficient of variation for each individual by month are shown 


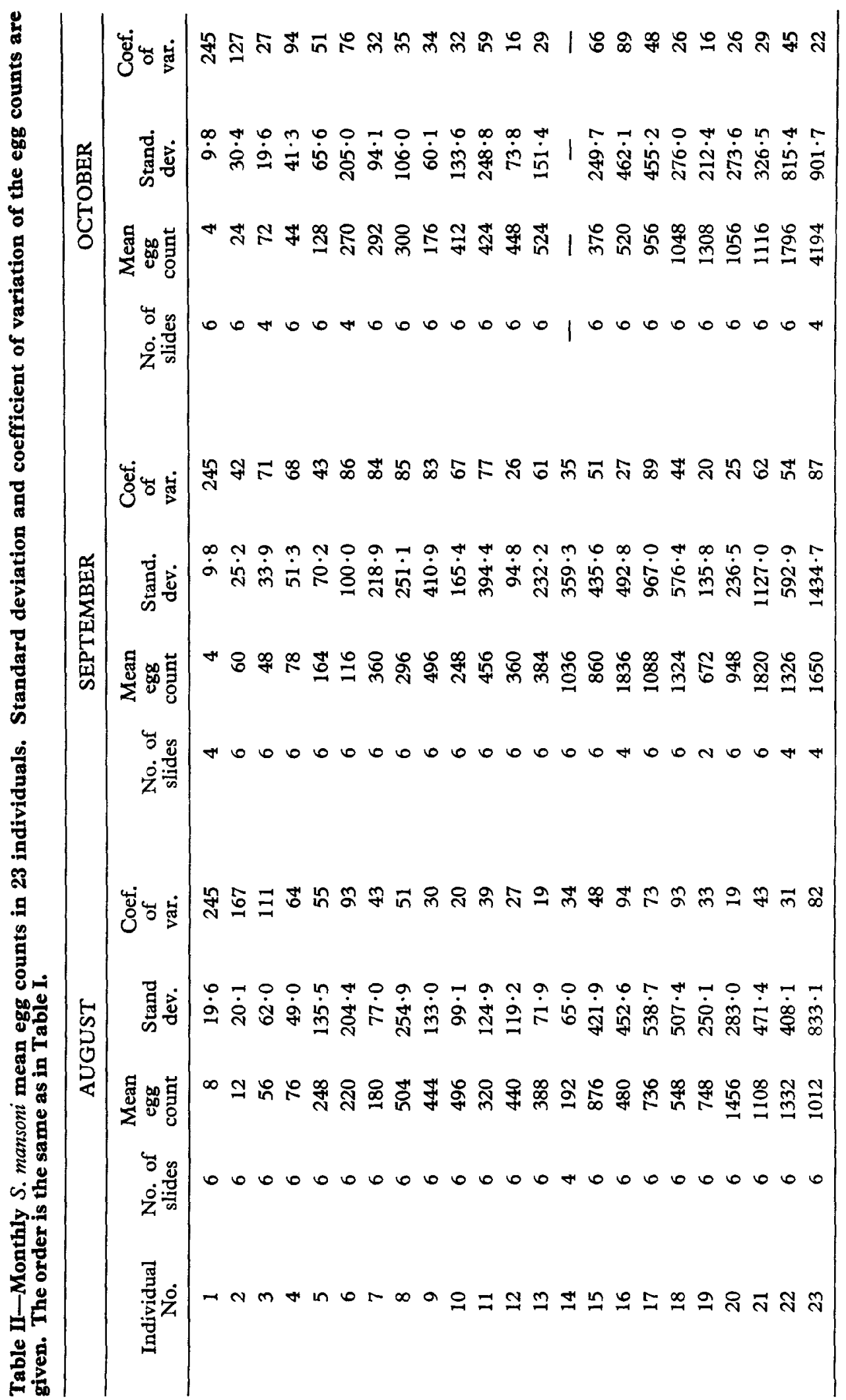


in Table II. There was month to month variation in egg counts, but the average coefficients of variation for each month were around $70 \%$, indicating that the counts, grouped by month, varied to a similar degree. When the mean egg counts for each month were plotted on a logarithmic scale (Fig. 1), there

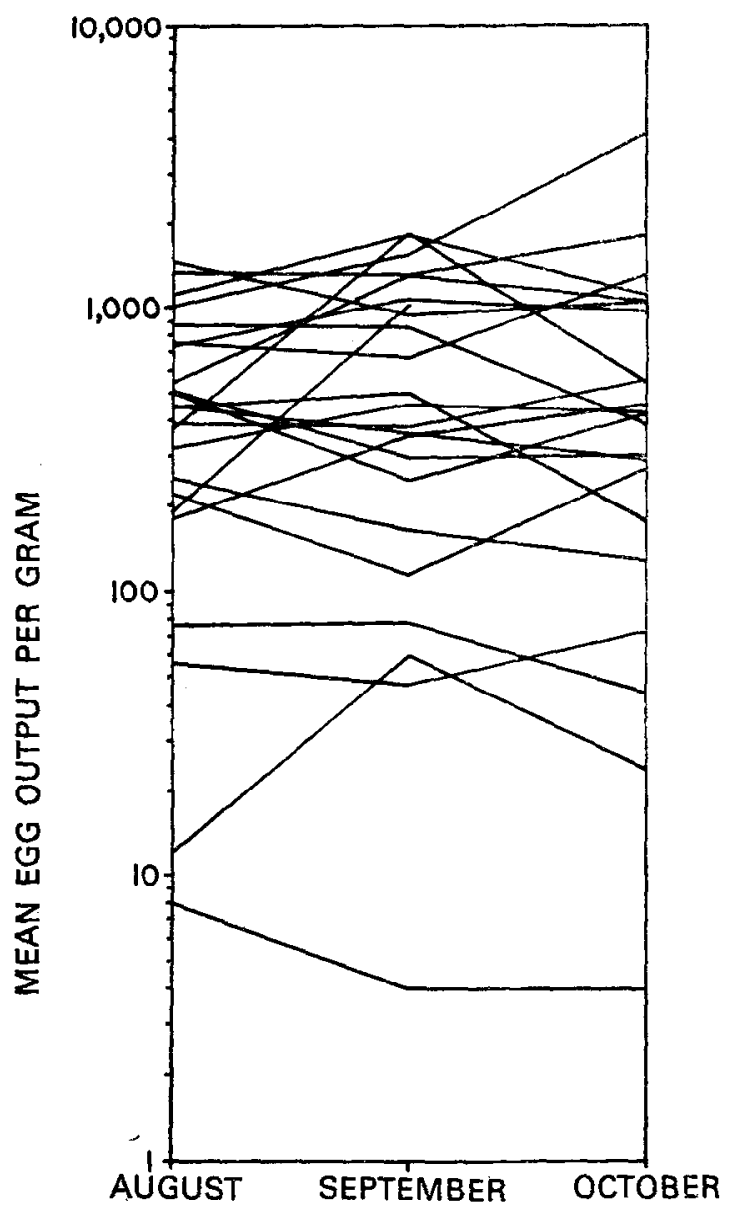

Fig. 1. Changes in mean $S$. mansoni egg output of 23 individuals over 3 months, plotted on logarithmic scales.

was apparent stability of counts for most individuals. However, further analysis of these raw data was not possible because of the strong correlation of the individual variances to the means, as demonstrated in Fig. 2. The linear relation suggested that transformation of the data was necessary in order to render the variances independent of the means. Thus, Taylor's power law (TAYLOR, 1961) has been used to suggest a precise transformation of the raw data. In the general case, the equation,

$$
\log s^{2}=\log a+b \log \overline{\mathrm{x}}
$$

when solved for $b$, indicates a specific type of transformation. In our data, $b$ was approximately $1 \cdot 4$ (Table III), and as these values of $b$ were close to 1.33 according to Taylor's power law, a cube-root transformation was appropriate. The second part of
Table III shows that when this transformation was made the correlation of variances to means disappeared, which was distinctly different from the highest significant correlations of the untransformed data.

The cube-root transformed data by month are presented in Table IV. There were few statistically significant (at the 5\% level) changes in egg counts, based on month-to-month comparisons of the transformed data. From August to September, three persons showed increased and two persons showed decreased mean counts; from September to October, only one person increased and one decreased.

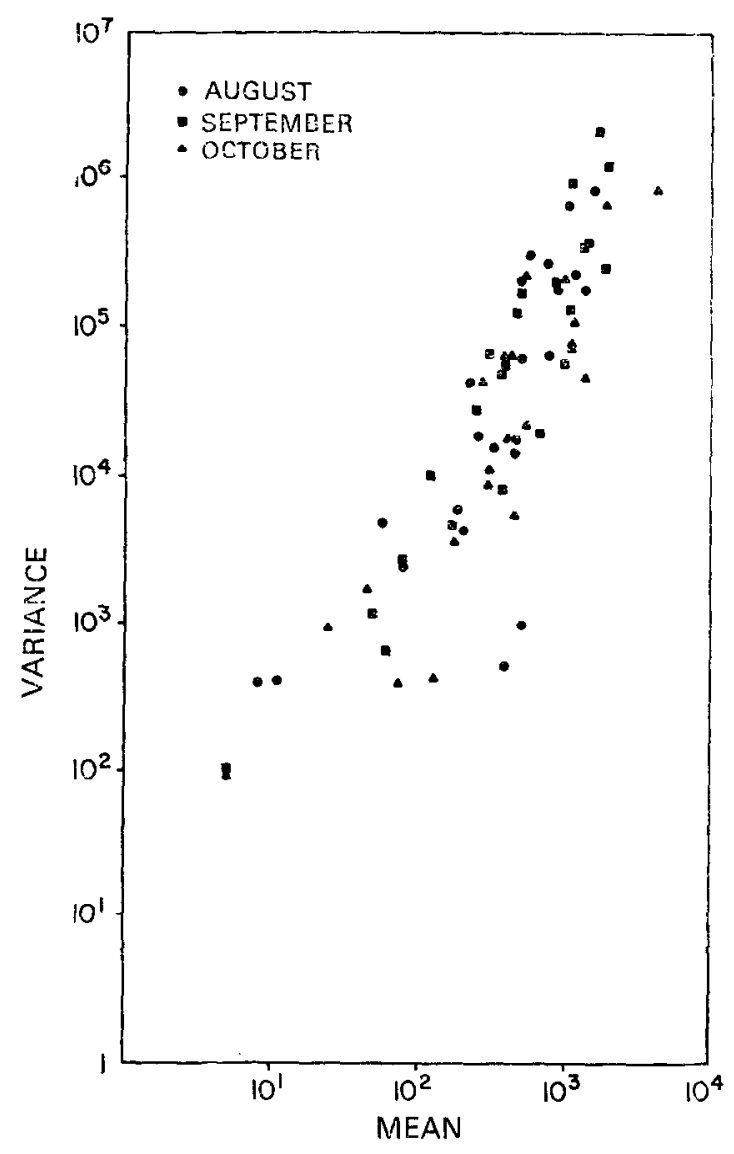

Fig. 2. The relationship between the mean and variance of monthly individual $S$. mansoni egg counts plotted on logarithmic scale. Each point represents the egg counts of one individual in one month.

In order to test for any important variations in the day-to-day egg excretions for the populations as a whole, the cube-root transformed data for three consecutive days in August were further transformed to a standardized mean of 15 for each individual for each day. This weighted mean was used to avoid the effects of very high or very variable egg counts on the over-all egg output. The mean transformed and weighted egg count was 
Table III-The relationship between the $S$. mansoni mean egg count and variance for each monthly series of examinations. The effect of cube root transformation on the data is shown

\begin{tabular}{|c|c|c|c|c|c|c|}
\hline Month & $\begin{array}{c}\text { Mean of } \\
\text { Means }\end{array}$ & $\begin{array}{l}\text { Mean of } \\
\text { Variances }\end{array}$ & $\begin{array}{l}\text { Gradient } \\
(\text { b })^{\star}\end{array}$ & $\begin{array}{c}\text { Correlation } \\
\text { Coefficient }\end{array}$ & $\begin{array}{l}\text { Degrees of } \\
\text { Freedom }\end{array}$ & $\begin{array}{c}\text { Significance } \\
\text { Level }\end{array}$ \\
\hline \multicolumn{7}{|c|}{ Logarithms of statistics from untransformed data } \\
\hline $\begin{array}{l}\text { August } \\
\text { September } \\
\text { October }\end{array}$ & $\begin{array}{l}2 \cdot 483 \\
2 \cdot 557 \\
2 \cdot 508\end{array}$ & $\begin{array}{l}4 \cdot 395 \\
4 \cdot 614 \\
4 \cdot 288\end{array}$ & $\begin{array}{l}1 \cdot 333 \\
1 \cdot 521 \\
1 \cdot 373\end{array}$ & $\begin{array}{l}0 \cdot 873 \\
0 \cdot 918 \\
0 \cdot 917\end{array}$ & $\begin{array}{l}22 \\
22 \\
21\end{array}$ & $\begin{array}{l}0 \cdot 1 \% \\
0 \cdot 1 \% \\
0 \cdot 1 \%\end{array}$ \\
\hline \multicolumn{7}{|c|}{ Statistics of cube root transformed data } \\
\hline $\begin{array}{l}\text { August } \\
\text { September } \\
\text { October }\end{array}$ & $\begin{array}{l}6 \cdot 9 \\
7 \cdot 5 \\
7 \cdot 4\end{array}$ & $\begin{array}{l}3 \cdot 1 \\
3 \cdot 1 \\
1 \cdot 5\end{array}$ & $\begin{array}{r}-0.080 \\
0.302 \\
-0.050\end{array}$ & $\begin{array}{l}0 \cdot 056 \\
0 \cdot 283 \\
0 \cdot 138\end{array}$ & $\begin{array}{l}22 \\
22 \\
21\end{array}$ & $\begin{array}{l}\text { NS } \\
\text { NS } \\
\text { NS }\end{array}$ \\
\hline
\end{tabular}

$\star$ as calculated according to Taylor's power law

Table IV-The mean and standard deviation of cube root transformed S. mansoni egg counts for individuals represented in Table I

\begin{tabular}{|c|c|c|c|c|c|c|}
\hline \multirow[b]{2}{*}{$\begin{array}{c}\text { Indi- } \\
\text { vidual } \\
\text { No. }\end{array}$} & \multicolumn{2}{|c|}{ AUGUST } & \multicolumn{2}{|c|}{ SEPTEMBER } & \multicolumn{2}{|c|}{ OCTOBER } \\
\hline & $\begin{array}{l}\text { Mean } \\
\text { egg } \\
\text { count }\end{array}$ & $\begin{array}{c}\text { Stand. } \\
\text { dev. }\end{array}$ & $\begin{array}{c}\text { Mean } \\
\text { egg } \\
\text { count }\end{array}$ & $\begin{array}{l}\text { Stand. } \\
\text { dev. }\end{array}$ & $\begin{array}{c}\text { Mean } \\
\text { egg } \\
\text { count }\end{array}$ & $\begin{array}{l}\text { tand. } \\
\text { dev. }\end{array}$ \\
\hline 1 & 0.6 & $1 \cdot 5$ & 0.5 & $1 \cdot 2$ & $0 \cdot 6$ & $1 \cdot 2$ \\
\hline 2 & $1 \cdot 1$ & $1 \cdot 7$ & $3 \cdot 8$ & 0.6 & $1 \cdot 8$ & $2 \cdot 0$ \\
\hline 3 & $2 \cdot 8$ & $2 \cdot 3$ & $3 \cdot 1$ & $1 \cdot 6$ & $4 \cdot 1$ & 0.4 \\
\hline 4 & $4 \cdot 1$ & 0.9 & $3 \cdot 7$ & $1 \cdot 9$ & $6: 0$ & $1 \cdot 7$ \\
\hline 5 & $6 \cdot 1$ & $1 \cdot 0$ & $5 \cdot 3$ & $1 \cdot 0$ & $4 \cdot 9$ & $0 \cdot 8$ \\
\hline 6 & $5 \cdot 0$ & $2 \cdot 9$ & $4 \cdot 5$ & $1 \cdot 4$ & $6 \cdot 2$ & $1 \cdot 4$ \\
\hline 7 & $5 \cdot 5$ & 0.9 & $6 \cdot 8$ & $1 \cdot 6$ & $6 \cdot 6$ & 0.7 \\
\hline 8 & $7 \cdot 8$ & $1 \cdot 3$ & $6 \cdot 1$ & $2 \cdot 2$ & $6 \cdot 6$ & $0 \cdot 8$ \\
\hline 9 & $7 \cdot 6$ & $0 \cdot 7$ & $7 \cdot 5$ & $2 \cdot 0$ & $5 \cdot 5$ & $0 \cdot 8$ \\
\hline 10 & $7 \cdot 9$ & 0.5 & $6 \cdot 0$ & $1 \cdot 5$ & $7 \cdot 4$ & $0 \cdot 8$ \\
\hline 11 & $6 \cdot 7$ & 0.9 & $7 \cdot 2$ & $2 \cdot 1$ & $7 \cdot 3$ & $1 \cdot 4$ \\
\hline 12 & $7 \cdot 6$ & $0 \cdot 7$ & $7 \cdot 1$ & $0 \cdot 6$ & $7 \cdot 6$ & $0 \cdot 4$ \\
\hline 13 & $7 \cdot 3$ & $0 \cdot 5$ & $6 \cdot 9$ & $1 \cdot 8$ & $8 \cdot 0$ & $0 \cdot 8$ \\
\hline 14 & $5 \cdot 7$ & $0 \cdot 6$ & $10 \cdot 0$ & $1 \cdot 3$ & - & - \\
\hline 15 & $9 \cdot 3$ & $1 \cdot 7$ & $9 \cdot 3$ & $1 \cdot 6$ & $7 \cdot 0$ & $1 \cdot 5$ \\
\hline 16 & $7 \cdot 3$ & $2 \cdot 1$ & $12 \cdot 2$ & $1 \cdot 1$ & $6 \cdot 1$ & $4 \cdot 7$ \\
\hline 17 & $8 \cdot 4$ & $2 \cdot 7$ & $9 \cdot 5$ & $3 \cdot 0$ & $9 \cdot 6$ & $1 \cdot 6$ \\
\hline 18 & $6 \cdot 6$ & $4 \cdot 2$ & $10 \cdot 8$ & $1 \cdot 6$ & $10 \cdot 1$ & 0.9 \\
\hline 19 & $9 \cdot 0$ & $1 \cdot 1$ & $8 \cdot 7$ & 0.6 & $10 \cdot 9$ & 0.6 \\
\hline 20 & $11 \cdot 3$ & 0.8 & $9 \cdot 8$ & $0 \cdot 8$ & $10 \cdot 1$ & 0.9 \\
\hline 21 & $10 \cdot 2$ & $1 \cdot 5$ & $11 \cdot 7$ & $2 \cdot 8$ & $10 \cdot 4$ & $1 \cdot 1$ \\
\hline 22 & $10 \cdot 9$ & $1 \cdot 3$ & $10 \cdot 8$ & $1 \cdot 6$ & $11 \cdot 9$ & $1 \cdot 8$ \\
\hline 23 & $9 \cdot 9$ & $2 \cdot 6$ & $11 \cdot 1$ & $3 \cdot 4$ & $16 \cdot 1$ & $1 \cdot 2$ \\
\hline
\end{tabular}

calculated for each of the three days (Table V), and compared (Student's $t$ test) with the expected mean of 15 . The calculated values were very close to 15 , indicating little over-all variation in the day-to-day egg excretion of the population.

In terms of the total egg excretion of the 23 study individuals, the transformed data by month showed a total increase of $6 \cdot 1 \%$ between August and September and a decrease of $0.4 \%$ between
Table $\mathrm{V}$-The mean and standard deviation of the standardized daily $S$. mansoni egg output in the study group during the month of August

\begin{tabular}{cccc}
\hline Day & $\begin{array}{c}\text { No. of } \\
\text { stools }\end{array}$ & Mean & $\begin{array}{c}\text { Stand. } \\
\text { dev. }\end{array}$ \\
\hline 1 & 19 & $15 \cdot 2$ & $1 \cdot 5$ \\
2 & 21 & $14 \cdot 8$ & $1 \cdot 5$ \\
3 & 22 & $14 \cdot 9$ & $1 \cdot 4$ \\
\hline
\end{tabular}

September and October. Additionally, the transformed individual mean counts of August and October were highly correlated $(r=0.94)$, These observations provide further evidence of relative stability of egg excretion.

Because interest has been shown in identification and treatment of persons with high egg counts, an analysis of the efficiency of detection of such individuals was made. 19 of the 23 persons had an egg count over 400 during the study (Table I). The first examination (in August) detected 13 of the $19(68 \%)$, the first three examinations detected 16 of the $19(84 \%)$, and the first five detected 18 of the $19(95 \%)$. One individual with a high count was detected on the eighth examination in September.

\section{Discussion}

Investigations of variation in faecal egg excretion in $S$. mansoni infection have been few in number. In the original and only detailed study, Scort (1938) followed three Egyptian farmers for one month and demonstrated coefficients of variation for $S$. mansoni egg output similar to those for egg excretion in Ancylostoma duodenale infection. ScotT suggested that quantitation of schistosome egg output might correlate with morbidity due to the infection and would have value as a direct measure of the contamination of the environment by infected individuals. He concluded that the degree of variation of $S$. mansoni egg excretion permitted 
analysis of the data especially if egg counts were expressed in terms of eggs per unit volume of stool rather than eggs per unit of time.

WARREN et al. (1974), in a study of 218 Yemeni immigrants in the USA, found no significant difference in egg counts between two stools taken three days apart. SIONGOK et al. (1976) evaluated stability of egg counts within a Kenyan population of 416 individuals by re-examining a random $10 \%$ of persons three weeks after the initial stool collection; $68 \%$ of the individuals remained within the original egg excretion class.

Stool egg count results in 142 St. Lucian children over a two to four year period were examined by Cook et al. (1974). Using designations of heavy (>400 eggs/gramme), moderate (100 to 300 ) and light (10 to 75$)$ egg counts, relatively good agreement between the initial and final grouping was shown; over two to four years, only four persons changed by more than one class.

With respect to $S$. haematobium infection MCCULLOUGH \& BRADLEY (1973) demonstrated that, despite considerable short-term fluctuations in egg output by Tanzanian children, the trend over three years was toward stabilization of counts. In particular, high egg excretors tended to remain high and low egg excretors low. They attributed this steady state to the existence of concomitant immunity, but this conclusion has been disputed (JORDAN et al., 1974).

In this study, we followed a group of individuals infected with $S$. mansoni for an intermediate time period, and based our analysis on that of McCullough \& Bradley (1973). Our objective was to test the hypothesis that egg excretion in schistosomiasis mansoni is sufficiently stable to allow conclusions to be drawn from one or two egg counts.

The data show a fairly large variation over a short period of time (i.e. three consecutive days in each of three months) as demonstrated by coefficients of variation of around $70 \%$. (It is interesting that MCCUllough \& BRADLEY, 1973, showed similar coefficients of variation within their collection periods.) Much of this variation is undoubtedly contributed by persons with low egg counts, particularly those who had counts of zcro. However, when the counts are analysed for the entire three-month period, using either the raw data or the transformed data, it is clear that egg excretion is relatively stable.

The results presented here confirm the utility of mathematical transformation of egg count data to render them more tractable to analysis. Although we used a specific transformation in the present analysis, i.e. Tayler's power law, the general use of logarithmic transformation and of geometric mean egg counts when describing age-intensity relationship for populations seems desirable.

Improved egg-counting techniques and the wide use of a standard methodology in various endemic areas will help define the natural history of schistosomiasis and how preventive or curative procedures should be deployed and evaluated. For example, if selective chemotherapy is to be used as recommended by WARREN \& MARMOUD (1976), it is necessary to know the efficiency of detection of high egg excretors by whatever counting technique is utilized.

In the present study, mean $S$. mansoni egg excretion and variance was stable over the threemonth period of observation. However, the variation between consecutive quantitative stool examinations must be emphasized. Only two-thirds of individuals demonstrated during the study to have high egg counts $(>400)$ were identified on the first examination using the modified Kato method. Each quantitative counting method must be evaluated in large populations in terms of efficiency and sensitivity, before use in selective mass treatment programmes. In spite of considerable variation between the results of consecutive examinations, over time there is considerable stability of egg excretion,

\section{Acknowledgements}

We are grateful to Dr. Italo Sherlock, Director of the Nucleo de Pesquisas da Bahia-FIOCRUZ, for his support; to Prof. David J. Bradley, London School of Hygiene and Tropical Medicine, for his advice; to Dr. Thomas $H$. Weller for critical review of the manuscript; to The Wellcome Trust, the Pan American Health Organization and Industria e Comercio de Mineracao (ICOMI) for financial support; to Elizabeth Allred for the illustrations; to Sr. Tome Silva de Oliveira for considerable field assistance; and, most of all, to the 23 individuals who co-operated in the study. $M$. L. Barretto is the recipient of a scholarship from the Brazilian National Council for Scientific and Technological Development (CNPq).

\section{References}

Bell, D. R. (1963). A new method for counting Schistosoma mansoni eggs in faeces with special reference to therapeutic trials. Bulletin of the World Health Organization, 29, 525-530.

Cheever, A. W. (1968). A quantitative post-mortem study of schistosomiasis mansoni in man. American fournal of Tropical Medicine and Hygiene, 17, 38-64.

Cook. J. A., Baker, S. T., Warren, K. S. \& Jordan, P. (1974). A controlled study of morbidity of schistosomiasis mansoni in St. Lucian children, based on quantitative egg excretion. American fournal of Tropical Medicine and Hygiene, 23, 625-633.

Jordan, P., Cook, J. A. \& Davis, A. (1974). Schistosoma haematobium infection: immunity or concomitant immunity? Transactions of the Royal Society of Tropical Medicine and Hygiene, 68, 340-341.

Katz, N., Chaves, A. \& Pellegrino, J. (1972). A simple device for quantitative determination of Schistosoma mansoni eggs in faeces examined by the thick-smear technique. Revista do Instituto de Medicina Tropical do São Paulo, 14, 397.

Kloetzel, K. (1974). "Selective" chemotherapy for schistosomiasis mansoni. Transactions of the Royal Society of Tropical Medicine and Hygiene, 68, 344.

Lehman, J. S., Jr., Mott, K. E., Morrow, R. H., Jr., Muniz, T. M. \& Boyer, M. H. (1976). The intensity and effects of infection with Schistosoma 
mansoni in a rural community in northeast Brazil. American fournal of Tropical Medicine and Hygiene, 25, 285-294.

McCullough, F. S. \& Bradley, D. J. (1973). Egg output stability and the epidemiology of Schistosoma haematobium. Part I. Variation and stability in Schistosoma haematobium egg counts. Transactions of the Royal Society of Tropical Medicine and Hygiene, 67, 475-490.

Martin, L. K. \& Beaver, P. C. (1968). Evaluation of Kato thick-smear technique for quantitative diagnosis of helminth infections. American Fournal of Tropical Medicine and Hygiene, 17, 382-391.

Mott, K. E., Lehman, J. S., Jr., Hoff, R., Morrow, R. H., Muniz, T. M., Sherlock, I., Draper, C. C., Pugliese, C. \& Guimaraes, A. C. (1976). The epidemiology and household distribution of seroreactivity to Trypanosoma cruzi in a rural community in northeast Brazil. American fournal of Tropical Medicine and Hygiene, 25, 552-562.

Scott, J. A. (1938). The regularity of egg output of helminth infections, with special reference to
Schistosoma mansoni. American fournal of Hygiene, 27, 155-175.

Siongok, T. K. A., Mahmoud, A. A. F., Ouma, J. H., Warren, K. S., Muller, A. S., Handa, A. K. \& Houser, H. B. (1976). Morbidity in schistosomiasis mansoni in relation to intensity of infection: study of a community in Machakos, Kenya. American fournal of Tropical Medicine and Hygiene, 25, 273-284.

Taylor, L. R. (1961). Aggregation, mean and variance. Nature, 169, 732-735.

Warren, K. S., Mahmoud, A. A. F., Cummings, P., Murphy, D. J. \& Houser, H. B. (1974). Schistosomiasis mansoni in Yemeni in California: Duration of infection, presence of disease, therapeutic management. American fournal of Tropical Medicine and Hygiene, 23, 902-909.

Warren, K. S. \& Mahmoud, A. A. F. (1976). Targeted mass treatment: A new approach to the control of schistosomiasis. Transactions of the Association of American Physicians, 89, 195-202.

Accepted for publication 28th November, 1977.

\section{New Fellows}

ABDULLA, M., M.B.B.S., Libya

ALPERS, M. P., B.SC., M.A., M.B., B.S., Papua New Guinea

BENGTSSON, E., M.D., D.T.M. \& H., Sweden

CAMPBELL, III, C. C., A.B., M.D., M.P.H., U.S.A.

CHOWDHURY, S. N., M.B., B.S., D.T.M., \& H.,

M.R.C.P., India

CURTIS, C. F., B.A., PH.v., Britain

DENNIS, E. A., PH.D., Liberia

DE PINERO, M. D. F., B.SC., Venezuela

DE SAVIGNY, D. H., B.SC., M.SC., Canada

EYCKMANS, L. A. F., M.D., Belgium

ABDULRAHMAN, F. A., PH.D., M.P.H., U.S.A.

IDRIS, M., M.B.B.S., L.R.C.P., D.T.M. \& H., M.D., Nigeria

INCANI, R. N., M.D., M.sC., Britain

KAGERUKA, P., M.v., Zaire

KLOTER, K. O., B.A., M.SC., M.P.H., U.S.A

KUMAR, A., M.B., M.SC., M.P.H., India

KURNIAWAN, L., M.D., M.SC., Indonesia

MCNEELEY, D. F., B.A., M.P.H., M.D., U.S.A.

MAGANU, E. T., B.SC., M.B., CH.B., Botswana

MAKUTO, D. G., M.B., CH.B., Rhodesia
MARINESCO, G., M.D., Romania

MENDIS, K. N., M.B., R.S., M.SC., Britain

MOLINEAUX, L., M.D., M.P.H., PH.D., Switzerland

MONADJEMI, M. P., M.D., Britain

NIAZI, A. D., M.B., CH.B., D.T.P.H., Iraq

NUTI, M., Italy

ODHIAMBO, T. R., M.A., PH.D., Kenya

OMOJU, C., N.C.E., Nigeria

OSWANA, M. M., M.D., D.T.M., \& H., Kenya

RIVAS, E. A., D.M., Panama

RUIZ-MALDONADO, R., M.D., Mexico

RUTASITARA, W. K., M.B., CH.B., D.P.H., M.SC., Tanzania

SCHWARTZ, D. A., B.A., M.S., U.S.A.

SEAL, D. V., M.R.C.S., L.R.C.P., M.B.B.S., M.R.C. PATH., Britain

SINGH, N., M.B.B.s., D.T.M. \& H., India

SMITH, K. G. V., M.I.Biol., Britain

SMITH, P. D., M.D., U.S.A.

SNOW, W. F., B.SC., PH.D., Kenya

THOMPSON, A., M.B., B.S., Britain

VAN DER KUYP, E., M.D., M.P.H., Suriname

WARD, R. D., B.SC., M.SG., PH.D., Britain 